\title{
O currículo brasileiro segundo o Censo Escolar
}

Rodrigo Travitzki

Professor do ensino médio, Doutor em Educação pela USP

E-mail: r.travitzki@gmail.com
Resumo: Neste estudo, exploramos as bases de dados do Inep em busca de informações a respeito do currículo no Brasil. Os dados do Censo Escolar, embora limitados nesse sentido, revelaram que: a) as disciplinas mais frequentes, ministradas a pelo menos $90 \%$ dos alunos de ensino fundamental e médio, são: Língua Portuguesa, Matemática, História, Geografia, Sociologia/Estudos Sociais, Filosofia e Ciências (ou Química, Física, Biologia); b) Filosofia e Sociologia foram rapidamente inseridas no cotidiano escolar, indo de $40 \%$ a $90 \%$ em quatro anos; c) Educação Física também é ministrada à grande maioria dos alunos (88\%); d) Artes está mais presente no ensino fundamental ( $89 \%$ ) do que no médio (66\%), enquanto em Inglês ocorre o inverso ( $57 \%$ e $86 \%$, respectivamente); e) ao todo, 34\% dos alunos têm aulas de Ensino Religioso, sendo que $89 \%$ deles estudam em escolas públicas e 0,6\% em escolas confessionais. Algumas interpretações desses resultados foram esboçadas.

Palavras-chave: Currículo. Disciplinas. Censo Escolar. Ensino religioso. 


\section{INTRODUÇÃO}

O debate sobre currículo nacional tem se intensificado nos últimos anos, no Brasil e em boa parte do mundo ocidental, em virtude, ao que parece, do crescimento e consolidação dos exames nacionais. Afinal, à medida que tais exames vão ampliando sua abrangência e, também, sua importância para educadores e alunos, os conteúdos avaliados por eles vão influenciando cada vez mais os currículos ${ }^{1}$. Com isso, diversas questões emergem no debate entre educadores, gestores, especialistas e formuladores de políticas públicas. 0 que ensinar? Como ensinar? Quando ensinar? Quem decide isso?

É curioso notar que, embora a causa geradora da discussão possa até ser nova, muitas das questões debatidas estão presentes entre educadores já há um bom tempo. No século XVII, por exemplo, Comênio já chamava a atenção sobre diversos aspectos do que se convencionou depois chamar de currículo. Ele escreveu, por exemplo, que tornará “os estudos mais fáceis e mais atraentes aos estudantes aquele que [...] Ihes sobrecarrega o menos possivel a memória, ou seja, apenas obriga a aprender de cor as coisas fundamentais, deixando correr livremente as outras coisas" (COMÊNIO, 2001, Fund. VI). Há uma questão implícita nesta afirmação que nos é bastante familiar: afinal, o que é realmente fundamental que todos aprendam e o que pode ser considerado opcional para cada um?

Tais questões são bastante pertinentes e têm ocupado boa parte do debate educacional no Brasil. Por um lado, a estrutura federativa, a diversidade cultural do país e os próprios documentos oficiais (como os Parâmetros Curriculares Nacionais) apontam para uma diversidade não apenas de concepções pedagógicas, mas também de conteúdos. Por outro lado, a necessidade de garantir igualdade de condições em um país desigual, assim como a necessidade de administrar a rede de ensino, sugerem que é preciso padronizar. Afinal, "se a diversificação e a flexibilização fossem verdadeiros princípios do planejamento curricular, este não seria centralizado como efetivamente o é" (DOMINGUES; TOSCHI, 2000). De fato, podemos considerar que o predomínio do "ponto de vista da gerência", da necessidade de padronização, provém do sistema de educação de massas, ancorado em uma ideia de gestão científica da educação (PACHECO, 2003).

Na Inglaterra, por exemplo, a implantação de um sistema de avaliação externa das escolas, fundamentado em um currículo nacional, se constituiu no eixo

O Enem, por exemplo, "tem cumprido um papel indutor das reformas, colocando em xeque a autonomia curricular dos sistemas de ensino [...]" (MINHOTO, 2009, p. 27). 
principal das chamadas políticas de responsabilização (accountability), cujo objetivo é aumentar a eficiência do sistema educacional (BROOKE, 2006). Vale a pena lembrar que a origem desse tipo de política, nos anos de 1980, coincide com a redução de custos nos serviços públicos de um modo geral e, em especial, na educação. 0 que nos ajuda a entender, em parte, por que a eficiência começa a tornar-se um problema tão central para o sistema educacional na virada do século. Afinal, eficiência é uma relação entre custos e benefícios.

Mas o que pode ser uma solução para a Inglaterra, um país não federativo com uma longa tradição de "gestão científica" do Estado, talvez não funcione bem no Brasil. Além disso, mesmo em outros países há certas críticas às políticas de responsabilização baseadas em testes nacionais, como a possibilidade de se inibir a criatividade escolar e empobrecer o currículo (GROVE, 1996). Com efeito, há quem se oponha à criação de um currículo nacional único, ao menos sob certas condições - como é o caso de Apple (1993), referindo-se à educação francesa.

Enfim, a problemática do currículo não pode ser abordada de maneira simplista e linear, pois a ela convergem debates que vão desde aspectos gerenciais e econômicos até questões filosóficas a respeito da natureza humana e do papel da ciência. Quando estamos diante de tal complexidade, é prudente buscar algumas evidências empíricas para ajudar no entendimento do problema e na tomada de decisões. Nesse sentido, buscamos neste breve trabalho garimpar os dados públicos do Instituto Nacional de Estudos e Pesquisas Educacionais Anísio Teixeira (Inep) com o objetivo de encontrar informações relevantes sobre o currículo brasileiro hoje. Antes de relatar esta pesquisa empírica, contudo, caberia tecer algumas reflexões mais amplas acerca da problemática curricular.

\section{BREVES REFLEXÕES SOBRE CURRÍCULO}

Quando falamos em currículo, nos referimos aos conhecimentos que queremos desenvolver nos futuros cidadãos e, também, ao processo de desenvolvimento gradual desses conhecimentos - a chamada "ascensão epistêmica”. Mas, afinal, o que é conhecimento? Segundo Winch (2013), há basicamente três significados distintos para a palavra conhecimento: a) saber por contato; b) saber que; c) saber como. Para o autor, quando falamos em conhecimento, normalmente nos referimos ao tipo (b) - inclusive quando o assunto é currículo -, o que ele considera um equívoco tanto do ponto de vista 
epistemológico, teórico, quando do ponto de vista prático. Winch defende a importância do conhecimento do tipo (c), que congrega os outros dois, como eixo principal do planejamento curricular com vistas à ascensão epistêmica.

Outra reflexão importante que pretendemos trazer ao leitor diz respeito à aparente oposição entre autonomia e heteronomia. A definição de um currículo comum impede a possibilidade de autonomia da escola e do professor? Por um lado, pode-se considerar a educação como uma atividade do tipo "artesanal”, ou seja, depende de relações interpessoais e decisões tomadas durante o processo pelos atores envolvidos. 0 extremo desse ponto de vista seria a ausência de parâmetros curriculares para o professor. Por outro lado, pode-se considerar também que o responsável último pela educação não é o professor, mas sim o Estado e que, para promover a igualdade, é preciso que todos estejam aprendendo a mesma coisa ao mesmo tempo. 0 extremo disso seria a adoção de uma apostila nacional única. Deixando de lado os extremos, ambos os lados, como em qualquer boa polêmica, fazem sentido. Em situações como essa, é preciso paciência, debate, clareza e, se não for pedir muito, criatividade.

Buscando caminhar nesse sentido, resgatamos o conceito de "autoorganização", potencialmente inspirador para aqueles que consideram importantes tanto a existência de um currículo mínimo quanto a autonomia das escolas e professores. A auto-organização ocorre "cada vez que o advento ou a reestruturação de uma forma, ao longo de um processo, se deve principalmente ao próprio processo - a características nele intrínsecas" (DEBRUN, 1996, p. 4).

Segundo Debrun, há algumas condições necessárias para que ocorra um processo auto-organizado em um dado sistema, dentre as quais destacamos: a) a existência de canais de comunicação (efetiva, evidentemente) entre os elementos do sistema; b) a formação de uma memória interna do sistema (o que torna o processo menos inteligível do ponto de vista externo); c) condições de contorno razoavelmente bem definidas. Para nosso propósito, vejamos o que seriam essas condições de contorno.

Um exemplo de processo auto-organizado conhecido é a célula de RayleighBénard (TRAVITZKI, 2007), que consiste em uma espécie de "sanduíche" em que os pães seriam duas lâminas de vidro e o recheio seria um líquido confinado no espaço entre elas. Embaixo disso há uma fonte de calor que gera correntes convectivas no líquido - ou seja, as moléculas mais quentes sobem enquanto as mais frias descem. À medida que o calor aumenta, aumentam 
as correntes convectivas, até que em um dado momento as moléculas se reorganizam, fazendo as correntes tomarem a forma de um hexágono (evitando, assim, que o "sanduíche" exploda). A formação desses hexágonos só ocorre porque, dentre outras coisas, as condições de contorno do sistema são estáveis: se, por exemplo, o espaço entre as lâminas de vidro variasse constantemente, não ocorreria a formação dos hexágonos e, portanto, não haveria auto-organização.

Queremos dizer, com tal analogia, que pode ser possível conceber um tipo de currículo comum que, para além de limitar as possibilidades da atividade docente àquelas em consonância com os objetivos e princípios do Estado, possa também ser um porto seguro, um ponto de partida, ou mesmo um estímulo para os professores serem criativos e se adaptarem à realidade local, sem perder de vista os objetivos mais amplos da educação nacional.

Azanha nos fornece um breve exemplo dessa ideia, agora aplicada ao campo da educação. Analisando a influência de alguns documentos oficiais na autonomia escolar, o autor considera que

\section{[...] o regimento comum é um obstáculo à autonomia, mas é um obstáculo relativamente imóvel porque estável. Nessas condições, ao longo do tempo, as escolas acabam conseguindo conviver com as normas regimentais e, muitas vezes, encontrando em suas lacunas veredas que permitem iniciativas autônomas (AZANHA, 1993, p. 44).}

Em suma, quando discutimos autonomia versus currículo, muitas vezes esquecemos que é mais fácil (e mais efetivo) ser autônomo quando os pressupostos estão claros. Nesse sentido, um currículo nacional bem definido, mas não muito extenso, pode facilitar a autonomia dos professores, não o contrário. Pode ajudar, principalmente, o professor menos experiente, que ainda não tem clareza do que é mais importante ser ensinado aos seus alunos.

\section{MÉTOdOS E PRESSUPOSTOS}

Sendo nosso principal objetivo o mapeamento das informações sobre currículo disponibilizadas pelo Inep, a fim de contribuir no debate sobre este tema, que tem se intensificado nos últimos anos no Brasil, optamos por trabalhar com os microdados disponibilizados publicamente, utilizando software livre. No caso, o programa R em uma plataforma Linux Mint.

A opção pelo uso de software livre tem fundamentos práticos e filosóficos. Além de estarem praticamente imunes a vírus, os sistemas GNU/Linux têm o 
código aberto e, portanto, é possível a qualquer um (que seja um especialista, evidentemente) olhar para o código-fonte (a linguagem escrita pelo programador) e modificá-lo ao seu bel-prazer, sem que possa ser processado por isso. 0 princípio filosófico que está por trás desse tipo de solução é o de que a informação deve ser livre. É o princípio da transparência, especialmente importante quando falamos das atividades humanas diretamente relacionadas a este estudo: educação, ciência e política.

O princípio da transparência de informação nos leva a optar não apenas pelo uso de software livre, mas também por bases de dados públicas, livres e informativas. No caso da educação, temos, por exemplo, as bases disponibilizadas pelo Inep ou pela Organização para a Cooperação $e$ Desenvolvimento Econômico (OCDE). Infelizmente, em ambos os casos, embora os dados estejam liberados, as entidades só fornecem scripts de leitura dessa informação (que facilitam a interpretação da mesma) em programas de estatística proprietários ${ }^{2}$, não fornecendo scripts para software livre, como o R.

Há, com isso, certas dificuldades inerentes à importação, que são resolvidas com rotinas automáticas e a leitura manual de cada arquivo "Leia-me" dos microdados (INEP, 2013). A partir dessa leitura, pudemos estabelecer as linhas gerais deste estudo, buscando informações sobre currículo da educação básica no Brasil. Isso nos levou aos arquivos do Censo Escolar que, pelo menos desde 2007, divulgam quatro tipos básicos de tabelas: a) escolas; b) turmas; c) matrículas; d) docentes. O nível de maior "resolução" nos dados do censo é o das matrículas (c), que se refere aos indivíduos. Contudo, as informações sobre currículo (no caso, sobre as disciplinas ministradas) estão presentes apenas nos dados de turmas (b) e docentes (d).

Observando o arquivo das turmas (b), há duas variáveis numéricas importantes: Duração e Número de Matrículas. Mas a Duração aqui se refere à turma, portanto não varia de disciplina para disciplina - sendo assim de pouca utilidade para nossos fins. A outra variável, diferentemente, é a base da maioria dos resultados descritos neste artigo. Ou seja, em todo momento que nos referirmos, aqui, ao número de alunos, estaremos nos baseando na variável Número de Matrículas do arquivo de turmas.

Observando os dados disponíveis, podemos imaginar limites e possibilidades dos dados do Censo Escolar para a investigação sobre currículo no Brasil. As possibilidades se constituem justamente no fundamento do texto que se No caso, o SPSS e o SAS. 
segue. Antes, contudo, é importante identificar um limite que talvez aponte novas possibilidades. Como vimos, há uma "duração" referente às turmas, não às disciplinas. Sobre estas, há apenas "1" ou “0”, ou seja: "tal turma cursou tal disciplina” ou não. No fundo, este é um dado muito limitado, até porque há grande homogeneidade nele. Não é possível traçar perfis curriculares muito diversificados se só sabemos um “sim ou não” relacionado a cada disciplina.

Sendo assim, temos uma proposta, a partir dessa limitação: usar este mesmo espaço da variável binária para o "número de horas semanais" que a turma tem com esta disciplina. Isso adicionaria informação ao banco de dados, sem no entanto aumentar seu tamanho3. Qualquer iniciativa nesse sentido seria proveitosa do ponto de vista da investigação sobre currículo no Brasil.

\section{Resultados}

\section{Descrição geral dos dados}

Desde 2007, o Censo Escolar coleta informações sobre as matérias lecionadas nas escolas de ensino fundamental e médio, num total de 28 disciplinas em 2012. Os microdados são relativamente estáveis nesse período em relação à estrutura e variáveis disponíveis, permitindo uma análise longitudinal consistente. Otamanho da amostra também se mostrou estável, principalmente a partir de 2008, como se vê na Tabela 1.

Tabela 1 - Número total de alunos por ano

\begin{tabular}{l|l}
\hline Ano & Total de alunos \\
\hline 2007 & 53.236 .881 \\
2008 & 54.284 .144 \\
2009 & 54.434 .636 \\
2010 & 54.131 .255 \\
2011 & 54.436 .318 \\
2012 & 54.757 .106 \\
\hline
\end{tabular}

Fonte: Censo Escolar.

Segundo o Censo Escolar de 2012, houve 2.422.680 turmas neste ano, distribuídas em 177.631 escolas. O tamanho médio das turmas foi de 23 alunos (desvio padrão $=14$ ). Tanto o tamanho das turmas quanto o das escolas tende a aumentar progressivamente nas etapas de ensino da educação básica, conforme se observa na Tabela 2.

3 Não ocuparia mais espaço partindo do princípio de que não há turmas com mais de nove horas semanais. Caso este não seja um bom pressuposto, podem-se definir dois algarismos para o "número de horas por ano", por exemplo - neste caso aumentando apenas uma coluna ao banco de dados. 
Tabela 2 - Caracterização das turmas e escolas

\begin{tabular}{l|c|c} 
Etapa de ensino & $\begin{array}{l}\text { Média de turmas } \\
\text { por escola }\end{array}$ & $\begin{array}{l}\text { Média de alunos por } \\
\text { turma }\end{array}$ \\
\hline Educação infantil & 4,4 & 15,9 \\
Ensino fundamental & 9,3 & 19,4 \\
Ensino médio & 9,8 & 28,6 \\
\hline
\end{tabular}

Fonte: Censo Escolar 2012.

A educação infantil foi realizada, em 2012, por 97.127 escolas, enquanto o ensino fundamental por 135.928 e o médio por 27.190. Algumas escolas, contudo, participam de mais do que uma etapa da educação básica. Mais precisamente: 100.444 (57\%) operam em apenas uma etapa, 71.760 (40\%) em duas e 5.427 (7\%) escolas operam nas três etapas de ensino.

\section{O currículo no Censo 2012}

Buscando aproveitar as informações sobre currículo disponíveis no Censo Escolar, calculamos a proporção de alunos que têm aulas de cada uma das disciplinas. Como já exposto anteriormente, não há informações sobre duração de cada disciplina, apenas se uma dada turma teve ou não cada disciplina. Sintetizamos essas informações nas tabelas 4 e 5, que correspondem respectivamente às disciplinas mais frequentes (acima de 90\%) e menos frequentes.

Tabela 3 - Percentual de alunos que têm aulas de cada disciplina em cada etapa de ensino

\begin{tabular}{l|l|l}
\hline Disciplina & EF & EM \\
\hline Língua Portuguesa & 99,0 & 97,9 \\
Matemática & 98,4 & 97,8 \\
Filosofia & 5,6 & 93,1 \\
História & 94,1 & 95,6 \\
Geografia & 93,8 & 95,7 \\
Sociologia/Estudos Sociais & 3,7 & 92,0 \\
Química & 0,6 & 95,9 \\
Física & 0,7 & 95,7 \\
Biologia & 0,4 & 96,3 \\
Ciências & 96,1 & 0,1 \\
\hline
\end{tabular}

Fonte: Censo Escolar 2012. 
O que talvez mais salte aos olhos é que há, afinal, uma espécie de "currículo brasileiro obrigatório" bem definido nas duas etapas, ao menos quando observamos dados oficiais e bastante genéricos, como estes.

Nota-se também que essas disciplinas estão presentes no cotidiano de praticamente todos os alunos aos quais se destinam, embora ainda seja possível questionar, por exemplo, a ausência de aulas de Ciências para 4\% dos alunos do ensino fundamental (no ensino médio, como se sabe, tal disciplina se desdobra em Física, Química e Biologia, motivo pelo qual praticamente desaparece nesta etapa).

Como seria de se esperar, as disciplinas mais presentes são Português e Matemática, especialmente no ensino fundamental. Destacam-se, ainda, as altas taxas de Filosofia e Sociologia, que eram bem diferentes em 2007 (Figura 3).

Esses resultados sugerem que, ao menos quando se observam informações oficiais e genéricas, as políticas públicas de educação - como a recente obrigatoriedade de Filosofia e Sociologia - estão surtindo efeitos no cotidiano escolar. Além disso, parte dessas disciplinas (História, Geografia, Sociologia, Filosofia) não é normalmente incluída em avaliações externas, que costumam focar em Matemática, língua escrita, como a Prova Brasil, por vezes incluindo Ciências, como o Pisa. Avaliações externas que incluem as chamadas ciências humanas, como o Enem, são mais raras. Assim, a alta incidência dessas disciplinas sugere que há outras forças moldando as escolhas curriculares das escolas, além da suposta pressão das avaliações externas.

Os resultados da Tabela 3 poderiam sugerir, por outro lado, uma grande influência da matriz de referências do Enem, visto que todas as disciplinas presentes são supostamente avaliadas por este exame. Contudo, percentuais semelhantes foram obtidos em 2008, um ano antes de o Enem criar a Matriz de Referência com as quatro áreas. Nesse sentido, o raciocínio poderia ser o inverso, inclusive: os formuladores do Enem sabiamente optaram por avaliar justamente aquilo que é mais universal no trabalho que os alunos fazem dentro das escolas.

Por fim, a Tabela 3, que reúne as "disciplinas universais", ainda nos leva a uma última linha de indagações. Na prática, tais disciplinas seriam o que há de mais próximo a um "currículo obrigatório". Mas por que foram essas as escolhidas? Por que não estão aqui as habilidades artísticas e corporais, por exemplo? Ou, inversamente, por que há tantas disciplinas aqui? Especialmente 
no ensino médio, onde já se supõe maior nível de diversificação de caminhos para os alunos, há nove "disciplinas obrigatórias", segundo nossa análise ${ }^{4}$. Além de Educação Física e Inglês (não Artes), que seriam, digamos, “quase obrigatórias".

Pois bem, vejamos agora, na Tabela 4, que corresponde às disciplinas menos frequentes no currículo. Nota-se que a Educação Física, embora ausente nos exames externos, está presente na grande maioria das turmas nas duas etapas de ensino. Tal incidência pode estar relacionada a uma ampla valorização das habilidades corporais no contexto escolar, assim como pode ser considerada uma evidência de que os alunos precisam de outros tipos de atividade - que não se resuma a ficar sentado escrevendo ou escutando - e que os educadores sabem disso. Explicações semelhantes podem ser dadas à incidência de Artes, em especial no ensino fundamental. Por outro lado, não deixa de ser preocupante, partindo dos princípios da educação integral, observar que $11 \%$ das crianças brasileiras não têm aulas de Artes e Educação Física na escola.

Tabela 4 - Percentual de alunos que têm aulas de cada disciplina em cada etapa de ensino

\begin{tabular}{l|l|l}
\hline Disciplina & EF & EM \\
\hline Educação Física & 88,7 & 86,6 \\
Artes & 88,7 & 66,1 \\
Inglês & 56,7 & 85,8 \\
Espanhol & 6,2 & 34,0 \\
Francês & 0,2 & 0,3 \\
Outra língua estrangeira & 1,4 & 3,1 \\
Língua Indígena & 0,4 & 0,1 \\
Ensino Religioso & 55,6 & 8,4 \\
Informática & 11,2 & 2,6 \\
Profissionalizante & 0,0 & 3,2 \\
Atendimentos especiais & 0,0 & 0,2 \\
Diversidade sociocultural & 0,0 & 0,2 \\
Libras & 0,2 & 0,2 \\
Disciplinas pedagógicas & 0,0 & 1,3 \\
Outras & 23,1 & 24,3 \\
\hline
\end{tabular}

Fonte: Censo Escolar 2012

Afinal, por que essas duas disciplinas não estão na tabela anterior? Evidentemente, há uma certa arbitrariedade nesta "objetividade estabelecida a posteriori" (acima e abaixo de 90\%), mas não deixa de ser importante

4 Considerando como "obrigatórias" aquelas que são ministradas a mais do que $90 \%$ dos alunos. 
perceber que é possível separar as disciplinas com um único critério quantitativo.

O ensino de Língua Indígena, por sua vez, é ministrado a uma parcela diminuta dos alunos, comparável às aulas de Francês. Curiosamente, segundo o Censo Demográfico de 2010, a população indígena corresponde a 0,47\% da população brasileira: a mesma porcentagem de alunos que são submetidos ao ensino de Língua Indígena no EF. Ou seja, segundo as estatísticas do Inep e do IBGE, há uma chance de que "todos" os índios e "apenas" os índios estejam estudando Língua Indígena nas escolas hoje no Brasil.

Vejamos outras duas questões suscitadas pelos dados da Tabela 4: em primeiro lugar, se no Brasil há tanta desigualdade em termos de capital cultural e os resultados ainda se encontram tão abaixo do desejável, não seria a taxa de atendimentos especiais muito pequena? Seria desejável uma proporção maior de alunos com disciplinas de atendimentos especiais? Evidentemente, não é possível aprofundar essa questão com os dados disponíveis, mas fica registrada a observação. Em segundo lugar, talvez possamos fazer indagação semelhante a respeito do ensino de Informática. Não seria uma parcela muito pequena dos alunos a lidar com este instrumental tão fundamental para a vida contemporânea? Claro que é preciso evitar o inchaço do currículo, sem ser levado a pensar que todo conhecimento considerado importante é insubstituível e, mais ainda, responsabilidade da escola. Além disso, é sabido que as novas gerações tendem a dominar mais facilmente as ferramentas digitais. Contudo, será que o motivo pelo qual $89 \%$ dos alunos não estão tendo aulas de Informática é porque já dominam essas habilidades? Ou porque as escolas consideram que tais habilidades são desenvolvidas paralelamente em outras disciplinas? Ou porque isso não seria papel da escola? Ou será que os motivos seriam menos "pedagógicos" do que estes? Caberia, talvez, uma investigação nesse sentido, em outro momento.

Um fato curioso é que há mais alunos tendo aulas de Inglês no ensino médio do que no fundamental, enquanto ocorre o oposto com as línguas indígenas. De qualquer forma, embora possa parecer evidente para o vulgo que seja melhor ensinar línguas nas idades mais tenras, este é um assunto controverso no que tange ao ensino de línguas estrangeiras (SINGLETON; LENGYEL, 1995).

Por fim, outro dado que chama a atenção é a alta taxa de Ensino Religioso para crianças e adolescentes, que passa da metade no ensino fundamental. É prudente verificar que tipos de escolas são essas, por exemplo, se são públicas ou privadas, dado que o Estado brasileiro é laico. 


\section{Presença de Ensino Religioso nas escolas brasileiras}

Em um Estado democrático e (portanto) laico, coexistem dois princípios que muitas vezes caminham em sentidos opostos: a liberdade de crença dos indivíduos e a independência de credo do coletivo, ou seja, das instituições estatais. A crença religiosa ocupa papel central nessa discussão. Em que medida esse tênue equilíbrio pode ser afetado pelo currículo escolar?

Observando os dados brutos, notamos que 807.520 turmas escolares foram submetidas à disciplina Ensino Religioso, o que corresponde a um terço do total. As turmas estão divididas entre os diferentes tipos de escola, conforme se vê na Tabela 5.

Tabela 5 - Taxa da disciplina Ensino Religioso nas turmas

\begin{tabular}{l|l|l|l}
\hline $\begin{array}{l}\text { D e p e n d ê n c i a } \\
\text { administrativa }\end{array}$ & Turmas (total) & $\begin{array}{l}\text { Turmas com } \\
\text { Ensino Religioso }\end{array}$ & $\begin{array}{l}\text { Percentual com } \\
\text { Ensino Religioso }\end{array}$ \\
\hline Federal & 10.585 & 44 & $0,4 \%$ \\
Estadual & 707.156 & 214.380 & $30,3 \%$ \\
Municipal & 1.233 .751 & 489.910 & $39,7 \%$ \\
Privada & 471.188 & 103.186 & $21,9 \%$ \\
\hline
\end{tabular}

Fonte: Censo Escolar 2012.

Como seriam tais resultados no nível de "alunos" em vez de "turmas"? Ao todo, segundo o Censo, há 55 milhões de alunos brasileiros distribuídos, conforme a Tabela 6.

Tabela 6 - Taxa da disciplina Ensino Religioso nos alunos

\begin{tabular}{l|l|l|l}
\hline $\begin{array}{l}\text { Dependência } \\
\text { administrativa }\end{array}$ & $\begin{array}{l}\text { Número total } \\
\text { de alunos }\end{array}$ & $\begin{array}{l}\text { Número de alunos } \\
\text { com Ensino Religioso }\end{array}$ & $\begin{array}{l}\text { Percentual de alunos } \\
\text { com Ensino Religioso }\end{array}$ \\
\hline Federal & 278.580 & 1.016 & $0,4 \%$ \\
Estadual & 20.097 .307 & 5.621 .372 & $28,0 \%$ \\
Municipal & 25.896 .349 & 10.730 .600 & $41,4 \%$ \\
Privada & 8.484 .870 & 2.070 .193 & $24,4 \%$ \\
\hline Total & 54.757 .106 & 18.423 .181 & $33,6 \%$ \\
\hline
\end{tabular}

Fonte: Censo Escolar 2012.

Nota-se que um terço dos alunos brasileiros tem aulas de Ensino Religioso, sendo a maior parte deles pertencente às escolas municipais e, também, às estaduais. As escolas federais, por sua vez, mostraram incidência nula dessa disciplina, o que pode estar relacionado ao seu caráter predominantemente tecnológico.

Na Figura 1 podemos visualizar melhor uma informação presente, embora não de forma direta, na Tabela 6. Somando os números absolutos de alunos, chegamos à conclusão de que $89 \%$ das crianças e adolescentes que têm 
aulas de religião estudam em escolas públicas, ou seja, financiadas pelo Estado laico. Nesse sentido, a alta incidência de Ensino Religioso nas escolas públicas é um fato que merece atenção.

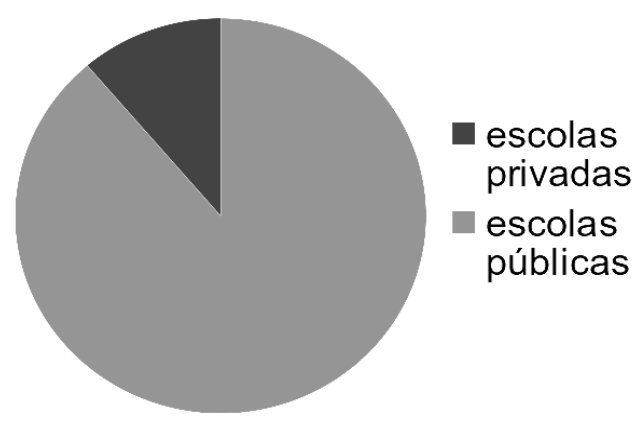

Figura 1 - Proporção entre as escolas em que há Ensino Religioso

Fonte: Censo Escolar 2012.

Afinal, um dos propósitos da existência de escolas privadas em uma democracia é a possibilidade de se criarem instituições educativas com costumes provenientes de diferentes religiões. Com efeito, a Lei de Diretrizes e Bases da Educação (LDB) prevê diferentes tipos de escola privada, sendo um deles voltado justamente para tal fim (as escolas privadas confessionais). No entanto, é nas escolas públicas que está a maior parte dos alunos submetidos a disciplinas de Ensino Religioso. Esta é uma questão que merece maior atenção.

Resta ainda, portanto, saber como se distribui tal disciplina entre os diferentes tipos de escola privada. São quatro os tipos de escola privada definidos pela LDB, conforme se vê na Tabela 7.

Tabela 7 - Taxa da disciplina Ensino Religioso nos alunos de escolas privadas

\begin{tabular}{l|l|l|l} 
Tipos de escola & $\begin{array}{l}\text { Total de } \\
\text { privada }\end{array}$ & $\begin{array}{l}\text { Alunos } \\
\text { com Ensino } \\
\text { Religioso }\end{array}$ & $\begin{array}{l}\text { Percentual de } \\
\text { alunos com Ensino } \\
\text { Religioso }\end{array}$ \\
\hline Particular & 6.585 .086 & 1.355 .818 & $20,6 \%$ \\
Comunitária & 235.289 & 24.266 & $10,3 \%$ \\
Confessional & 103.394 & 71.377 & $69,0 \%$ \\
Filantrópica & 1.561 .101 & 618.732 & $39,6 \%$ \\
\hline
\end{tabular}

Fonte: Censo Escolar 2012.

Nota-se que há uma boa quantidade de alunos nas escolas confessionais que não têm aulas de Ensino Religioso, chegando a 30\%, o que provavelmente significa que não há aulas de tal disciplina em todas as séries nessas escolas. Curiosamente, a maior parte do Ensino Religioso se concentra em 
escolas particulares, seguidas das filantrópicas. Juntas, as duas totalizam $95 \%$ dos alunos de escolas privadas que têm aulas de Ensino Religioso. As escolas confessionais, por sua vez, abrigam 3\% desses alunos. Em relação ao total de alunos, as confessionais respondem por $1 \%$ das escolas privadas, que são $15 \%$ do total. 0 alto número de alunos com Ensino Religioso nas escolas filantrópicas, diferente do baixo número nas confessionais, pode ser considerado coerente e compreensível segundo as definições da LDB, a depender das características da escola e de sua relação com a comunidade e com as finanças.

Restam ainda, dentre outras, dúvidas referentes às causas dessa informação, dessa “migração" do Ensino Religioso das escolas privadas confessionais (onde deveria estar, segundo a Lei) para as escolas públicas (onde está, segundo o Censo).

\section{Análise longitudinal 2007-2012}

Boa parte ${ }^{5}$ das disciplinas mais frequentes (Tabela 3 ) segue um padrão similar: em 2007 atingia entre 80\%-90\% dos alunos, aumentando já em 2008 para a quase totalidade, seguindo então de maneira estável nesse novo patamar tal como se vê na Figura 2. O que poderia significar tal padrão? Ao que parece, há um grupo de disciplinas caracterizado aí. Elas são hoje praticamente universais, e já eram quase isso no primeiro ano em que o Censo Escolar começou a recolher ${ }^{6}$ informações sobre disciplinas.

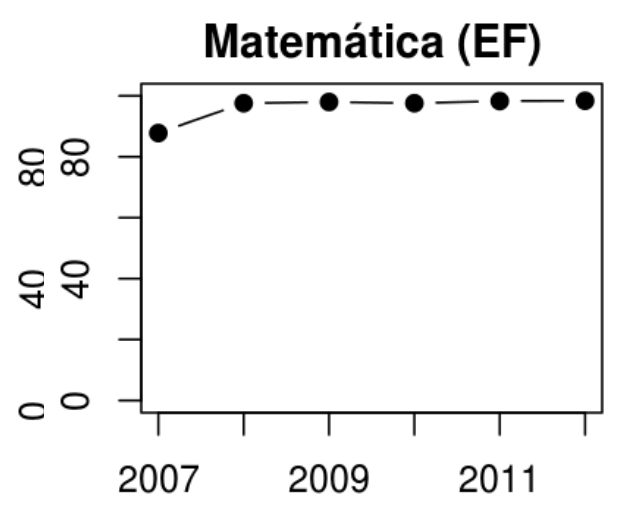

Figura 2 - Percentual de alunos com aula(s) dessas disciplinas, por ano Fonte: Censo Escolar.

São elas, além de Matemática e Língua Portuguesa: Química, História, Física, Geografia, Biologia e Ciências.

6 Ou ao menos divulgar essas informações nos microdados. 
Podemos considerar que a curva mais acentuada no primeiro ano pode estar relacionada a problemas de medida, como, por exemplo, seu caráter inédito ${ }^{7}$ que, por hipótese: a) fez com que alguns gestores não tenham preenchido completamente o questionário, por desconhecer esta nova parte - nesse caso, a medida estaria subestimada; b) estimulou as escolas a alterarem suas estruturas em apenas um ano - sendo, nesse caso, uma boa medida; c) fez as escolas mudarem mais a "maquiagem" (nomes, categorias) do seu trabalho cotidiano, para rapidamente se adequarem formalmente às novas normas sendo, nesse caso, uma medida superestimada. Em suma, há várias hipóteses distintas para tentar explicar o padrão mostrado na Figura 2, que se aplica a um certo grupo de “disciplinas universais".

Outro padrão encontrado, menos frequente, foi o da curva ascendente, como se vê na Figura 3. As mudanças que a figura descreve parecem estar, de fato, atreladas a políticas públicas, no caso, a inclusão de Filosofia e Sociologia (que substituiu a antiga Estudos Sociais) como disciplinas obrigatórias, provavelmente a principal causa do crescimento dessas duas disciplinas durante os últimos anos. Assim, a força da lei parece ser um fator influente no currículo brasileiro, ao menos quando observamos os (limitados) dados oficiais e públicos.
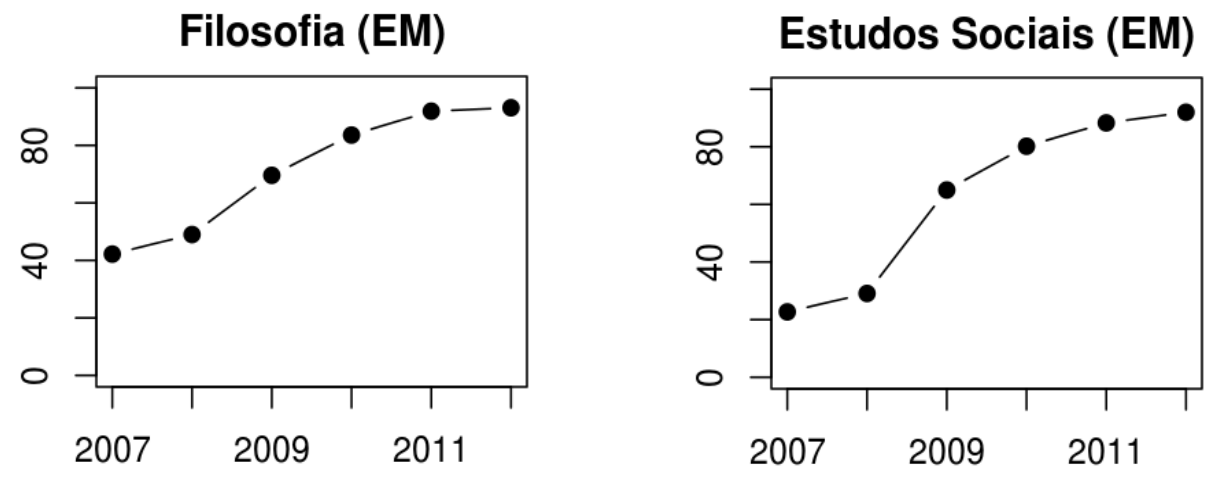

Figura 3 - Percentual de alunos com aula(s) dessas disciplinas

Fonte: Censo Escolar.

Os padrões das figuras 2 e 3 e as disciplinas a eles vinculadas sugerem que há fatores importantes atuando no currículo, que não são necessariamente gerados pelos testes padronizados, mas talvez pela existência de certos cursos de licenciatura. Isso seria, digamos, uma distorção epistemológica: é como se houvesse uma "reserva de mercado" a certos tipos de conhecimento

As disciplinas começaram a ser publicadas somente a partir de 2007 nos microdados do Censo Escolar. 
em decorrência não de sua natureza ou de sua importância para a sociedade, mas sim da natureza daqueles que detêm o monopólio para ensinar tal conhecimento. Esta é apenas mais uma hipótese levantada a partir dos dados do Censo Escolar, que merece ser mais bem investigada posteriormente.

Hátambém percursos moderadamente ascendentes, como de algumas línguas, a saber, Inglês no EF e Espanhol no EM. E, por fim, há uma única disciplina com padrão claro de curva descendente. Na verdade, não é exatamente uma disciplina: é justamente a categoria que representa as "outras disciplinas", ou seja, as que não foram mapeadas pelo Censo (Figura 4). Esta poderia ser, talvez, uma evidência de empobrecimento curricular. Por outro lado, com tantas disciplinas obrigatórias (e universais) e outras disciplinas se tornando mais frequentes, é praticamente inevitável que se diminua a categoria "outros", dado que o tempo na escola é limitado.

\section{Outras disciplinas (EF)}

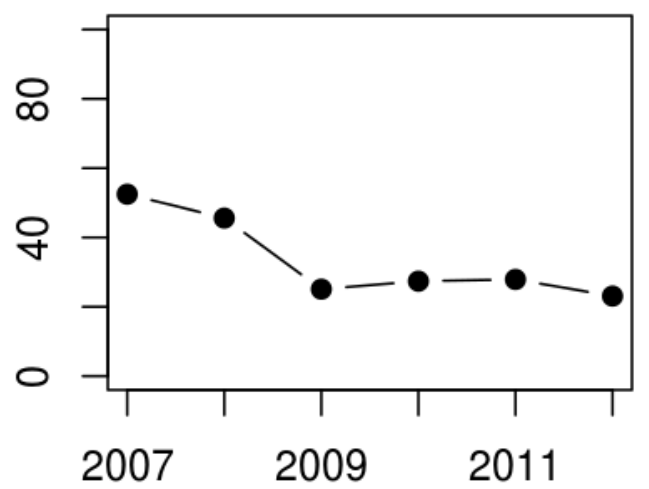

Figura 4 - Percentual de alunos com aula(s) de disciplinas não perguntadas no questionário

Fonte: Censo Escolar.

Mas fica aqui registrada a Figura 4 como a única evidência encontrada, até o momento, a favor da hipótese do estreitamento curricular induzido por avaliações externas - e uma evidência fraca nesse sentido. Por outro lado, as evidências contra essa hipótese foram mais frequentes nos dados analisados aqui. Vejamos as séries temporais das disciplinas de Artes e Educação Física na Figura 5, por exemplo. 
Artes (EF)
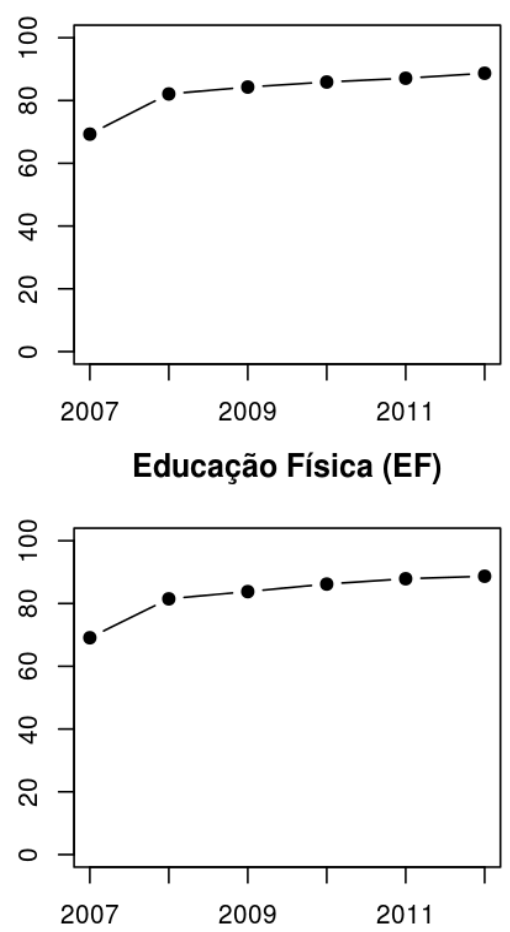

Artes (EM)
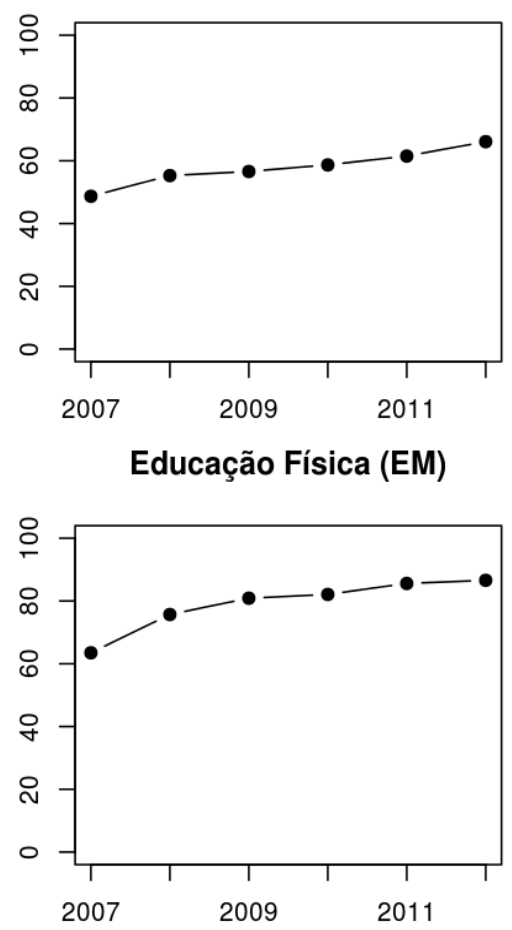

Figura 5 - Percentual de alunos com aula(s) dessas disciplinas Fonte: Censo Escolar.

Partindo do pressuposto de que as escolas só ensinam o que os testes externos avaliam, fica difícil compreender as altas taxas de alunos com aulas de Artes e Educação Física. Como consequência, tal pressuposto deve ser abandonado, ao menos nessa formulação "absoluta". 0 que mais chama a atenção, nesse sentido, é que as duas disciplinas estão sistematicamente ampliando sua abrangência desde 2007, quando os testes externos começavam a dar mais retorno às escolas, através da publicação do Ideb e do "ranking do Enem" (TRAVITZKI, 2013), gerando uma política de responsabilização das escolas.

Sendo assim, a Figura 5 mostra que os testes externos não determinam tudo o que acontece dentro de uma escola, embora possam ter considerável influência. Há, portanto, outras forças atuando na constante remodelagem do currículo. Que forças seriam essas, no caso de Artes e Educação Física? Será que as escolas e os pais não abrem mão da formação integral do ser humano? Será que há muitos artistas e esportistas formados pelas licenciaturas? Será que são os únicos momentos em que os alunos saem das cadeiras e dos livros? Enfim, essas são apenas algumas perguntas que fazem parte do debate. 
Os dados atualmente disponibilizados pelo Inep são bastante limitados no que diz respeito ao currículo, visto que o Censo Escolar informa apenas se certa disciplina foi ministrada ou não a determinada turma. Não obstante, foi possível analisar alguns aspectos gerais do currículo brasileiro com base nesse tipo de informação.

Identificamos algumas “disciplinas universais”, ministradas a pelo menos $90 \%$ dos alunos: Língua Portuguesa, Matemática, Filosofia, História, Geografia, Sociologia/Estudos Sociais, além das ciências naturais (Ciências no ensino fundamental e Química, Física e Biologia no ensino médio). A rápida ascensão, desde 2007, de Filosofia e Sociologia, sugere que as recentes políticas de "currículo obrigatório" surtiram efeito, ao menos no nível genérico do Censo.

Algumas disciplinas não avaliadas por testes externos (Educação Física e Artes) são amplamente, e cada vez mais, ministradas aos alunos brasileiros, o que pode ser uma evidência contra a tese de que os testes externos empobrecem o currículo, ao menos nesses casos. A disciplina de Artes se mostrou menos frequente no ensino médio do que no fundamental, o que poderia ser uma evidência a favor da tese, mas de forma bastante especulativa. A Educação Física foi mais uniforme nas duas etapas, o que pode estar relacionado a uma ampla valorização das habilidades corporais ou, quem sabe, a um mecanismo de compensação da disciplina corporal imposta pelo cotidiano escolar. Uma possível evidência a favor da tese da redução curricular via testes externos foi a sistemática redução de "outras disciplinas” no ensino fundamental mas não seria uma evidência forte, segundo nossa análise. De modo geral, os dados do Censo não permitem confirmar tal hipótese, sendo necessárias informações mais detalhadas a respeito dos currículos escolares para uma investigação mais consistente a respeito.

Um dado que chamou a atenção foi a grande quantidade de alunos com aulas de Ensino Religioso $(33,6 \%)$ no Brasil. Chega a ser preocupante notar que $89 \%$ desses alunos estão em escolas públicas, financiadas pelo Estado laico, embora a LDB defina um tipo específico de escola privada para finalidades religiosas.

Por fim, algumas reflexões mais amplas foram feitas. Em primeiro lugar, consideramos importante, no debate sobre currículo, não reduzir o conhecimento ao "saber que", sendo necessário também tratar do "saber como", assim como do conhecimento obtido pelo contato direto com os processos e objetos. 
Consideramos também que é desejável conceber a relação entre autonomia e currículo de forma não dicotômica, partindo do princípio de que é mais fácil ser autônomo quando os pressupostos são claros e estáveis. Nesse sentido, um currículo nacional bem definido, mas não muito extenso, poderia até facilitar a autonomia dos professores. Fundamentamos essa ideia no conceito de auto-organização, proveniente da cibernética.

Um desafio que se coloca para quem pensa o currículo brasileiro hoje é: como enxugar sem empobrecer? Como definir o mínimo sem reduzir o máximo? Ou, melhor ainda: que tipo de currículo poderia estimular a criatividade docente sem, com isso, pôr em risco a qualidade do trabalho feito nas escolas? Afinal, entendemos que agir com liberdade não é agir sem ser constrangido por regras, mas sim agir segundo seu próprio entendimento da realidade. 


\section{Brazilian curriculum according to school census}

Abstract: On this paper we explore INEP's databases looking for information about curriculum in Brazil. School census' data, while limited in this sense, show that: a) more frequent disciplines, taught to at least $90 \%$ of Elementary and High-school education students are: Portuguese, Mathematics, History, Geografia, Sociology/Social Studies, Philosophy, and Science (or Chemistry, Physics, Biology); b) Philosophy and Sociology were quickly introduced in the school quotidian, growing from $40 \%$ to $90 \%$ in four years; c) Physical Education is also available to most of the students ( $88 \%)$; d) Arts is more present in Elementary Education (89\%) than High School (66\%), while the opposite happens with English (57\% and 86\% respectively); e) as a whole, 34\% of students attend Religious Education, $89 \%$ of which from public schools and $0,6 \%$ from confessional schools. Some interpretations of these results have been outlined.

Keywords: Curriculum. Disciplines. School census. Religious education. 


\section{REFERÊNCIAS}

APPLE, M. W. The politics of official knowledge: Does a national curriculum make sense? Teachers College Record, Nova York, v. 95, n. 2, inverno 1993.

AZANHA, J. M. P. Autonomia da escola, um reexame. Série Idéias, São Paulo, FDE, n. 16, p. 37-46, 1993.

BROOKE, N. O futuro das políticas de responsabilização educacional no Brasil. Cadernos de Pesquisa, São Paulo, v. 36, n. 128, p. 377-401, maio/ago. 2006.

COMÊNIO, J. A. Didactica Magna. Lisboa: Fundação Calouste Gulbenkian, 2001.

DEBRUN, M. A ideia de auto-organização. Coleção CLE, Campinas, Centro de Lógica - Unicamp, n. 18, 1996.

DOMINGUES, J.; TOSCHI, N. S. A reforma do ensino médio: a nova formulação curricular e a realidade da escola pública. Educação \& Sociedade, Campinas, v. 11, n. 70 , p. 63-79, 2000.

GROVE, E. Creativity and accountability in competency-based language programmes: Issues of curriculum and assessment. Melbourne Papers in Language Testing, v. 5, n. 1, p. 1-18, 1996.

INEP. Inep - microdados para download. Disponível em: 〈http://portal.inep. gov.br/basica-levantamentos-acessar». Acesso em: 1 maio 2013.

MINHOTO, M. A. Modelação curricular do ensino médio: análise de prescrições legais e do papel da avaliação dos sistemas de ensino. Jornal de Políticas Educacionais, v. 5, p. 27-36, 2009.

PACHECO, J. A. Competências curriculares: as práticas ocultas nos discursos da reforma. Revista de Estudos Curriculares, v. 1, n. 1, p. 57-75, 2003.

SINGLETON, D.; LENGYEL, Z. The age factor in second language acquisition: A critical look at the critical period hypothesis. In: The age factor in second language acquisition. Clevedon: Multilingual Matters, 1995.

TRAVITZKI, R. A neurodinâmica pode explicar a consciência? Uma análise da proposta de Walter Freeman. São Carlos: UFSCar, 2007.

. Enem: limites e possibilidades do Exame Nacional do Ensino Médio enquanto indicador de qualidade escolar. 2013. Tese (Doutorado em Educação) 
- Faculdade de Educação, Universidade de São Paulo, São Paulo, 2013.

WINCH, C. Curriculum design and epistemic ascent. Journal of Philosophy of Education, v. 47, n. 1, p. 128-146, 13 fev. 2013.

RECEBIDO: Janeiro de 2014.

APROVADO: Fevereiro de 2014. 